\title{
Camembert-type cheese quality and safety implications in relation to the timing of high-pressure processing during aging
}

\author{
Danton Batty, Lisbeth Meunier-Goddik, and Joy G. Waite-Cusic* \\ Department of Food Science and Technology, Oregon State University, Corvallis 97331
}

\section{ABSTRACT}

Bloomy rind cheeses, including Brie, Camembert, and related varieties, are at high risk of contamination by environmental pathogens during manufacture and ripening. This risk is particularly high during ripening due to open-air exposure of the product. Currently, no kill step is applied after manufacture or post ripening to control food safety risks associated with Listeria monocytogenes contamination. Instead, cheesemakers must rely on sanitation and environmental monitoring to reduce this risk. High-pressure processing (HPP) is a nonthermal food-processing technology that can effectively reduce bacterial contaminants with minimal impact on the organoleptic properties of various foods. The objective of this study was to evaluate HPP as a potential intervention to maintain Camembert cheese quality and reduce risk associated with L. monocytogenes. Timing of HPP treatments $(3,11$, and $45 \mathrm{~d}$ after manufacture) was based on the growth of L. monocytogenes during Camembert cheese ripening. High-pressure processing treatment of fully ripened cheeses (45 d) resulted in destruction of the surface mold, which caused browning and yellowing of the cheese rind. Applying HPP treatment earlier in the ripening process $(11 \mathrm{~d})$ resulted in a similar degradation of cheese appearance, which did not improve with continued ripening. Applying HPP treatment shortly after production $(3 \mathrm{~d}$; before the surface flora developed) delayed the development of the cheese rind and the textural ripening of the cheese. This early treatment time also resulted in free whey being expelled from the cheese, creating a firmer body. Applying HPP $11 \mathrm{~d}$ after manufacture resulted in $>5 \mathrm{log}$ reduction of L. monocytogenes at 450 and 550 $\mathrm{MPa}$ with holding times of $10 \mathrm{~min}$. Although HPP was effective at reducing $L$. monocytogenes associated with bloomy rind cheeses, the quality deterioration would be unacceptable to consumers. Cheesemakers must

Received December 31, 2018.

Accepted May 7, 2019.

*Corresponding author: joy.waite-cusic@oregonstate.edu continue to emphasize sanitation and environmental monitoring to reduce the risk of $L$. monocytogenes in bloomy rind cheeses.

Key words: bloomy rind cheese, stabilized cheese, Listeria monocytogenes, Camembert, high-pressure processing

\section{INTRODUCTION}

Bloomy rind cheeses, including Camembert and Brie, belong to the soft surface-ripened category of cheeses that originated in France (Shaw, 1981). These cheeses make up a significant portion of the specialty cheese market and are now produced around the world. Many varieties of bloomy rind cheeses are produced using different recipes and cheesemaking practices; however, they all rely on surface yeasts and molds for ripening. The predominant fungi associated with bloomy rind cheeses include Penicillium candidum, Geotrichum candidum, and Kluyveromyces marxianus (Leclercq-Perlat, 2011). These yeasts and molds are not only important for cheese ripening but give these cheeses their distinctive white-gray appearance (Shaw, 1981; Galli et al., 2016).

Many soft cheeses, including bloomy rind cheeses, are open-air ripened and are therefore at high risk of contamination from environmental pathogens, specifically Listeria monocytogenes (Choi et al., 2016). Between 1986 and 2008, the United States had 22 recalls associated with L. monocytogenes in soft-ripened cheeses (CDC and Health Canada, 2015). Between 1995 and 2013, 151 reported illnesses and 20 deaths worldwide were linked to Camembert and Brie consumption (CDC and Health Canada, 2015).

The high risk of contamination for bloomy rind cheese is due to many factors, including cheese composition and physicochemical changes during ripening, high frequency of handling, and lack of a process intervention after manufacture (CDC and Health Canada, 2015). During the ripening process, a unique environment is created, which supports the growth of L. monocytogenes (Ryser and Marth, 1987). The increase in $\mathrm{pH}$ and elevated ripening temperatures (up to $15^{\circ} \mathrm{C}$ ) sustain or 
encourage growth of psychrotrophic microorganisms (CDC and Health Canada, 2015). This growth is particularly concerning because cheesemaking environments and ripening areas have previously been identified as niches for L. monocytogenes (Muhterem-Uyar et al., 2015). Camembert-type cheeses are typically open-air aged for up to 2 wk to encourage fungal growth on the cheese surface. This prolonged environmental exposure and frequent handling increases the likelihood of $L$. monocytogenes coming into contact with the cheese and contaminating it. Currently, sanitation practices are the primary method of control to reduce the risk of $L$. monocytogenes contamination in bloomy rind cheeses.

High-pressure processing (HPP) is a nonthermal food-processing technology that is used to improve the microbial safety and delay spoilage of fresh oysters, processed meats, guacamole, fruit juice, and fresh cheeses. For these foods, minimal or no quality changes (visual, texture, etc.) are noticeable between the "raw" product and the HPP-treated product (Yordanov and Angelova, 2010). The efficacy of HPP in reducing L. monocytogenes has been demonstrated for several soft cheeses, including queso fresco, starter-free fresh cheese, fresh goat cheese, and model washed-curd cheese. Tomasula et al. (2014) observed significant destruction (4.6 log $\mathrm{cfu} / \mathrm{g}$ ) of L. monocytogenes with treatment at $600 \mathrm{MPa}$ for $5 \mathrm{~min}$ in queso fresco cheese. Evert-Arriagada et al. (2018) observed reductions for 2 strains of Listeria monocytogenes (CECT 4031 and ScottA) and Listeria innocua (CECT910) at pressures greater than $400 \mathrm{MPa}$ for $5 \mathrm{~min}$. Evaluating fresh goat cheese, Gallot-Lavallee (1998) achieved >5-log reduction of L. monocytogenes, using processing parameters of $550 \mathrm{MPa}$ for $5 \mathrm{~min}$ and $450 \mathrm{MPa}$ for $10 \mathrm{~min}$. Using a model washed-curd cheese matrix, a similar result was observed, with $L$. monocytogenes being reduced by $\sim 5 \log \mathrm{cfu} / \mathrm{g}$ at $500 \mathrm{MPa}$ for 5 and 20 min (López-Pedemonte et al., 2007). These studies suggest that HPP could be an effective processing strategy to reduce L. monocytogenes in bloomy rind cheeses.

Bloomy rind cheeses present a particular challenge in that their ripening is a dynamic combination of microbial metabolism and extracellular enzymatic activity. These reactions transform a firm and chalky curd into a complex cheese structure with a distinct outer rind and a soft interior that flows when cut (Gripon, 1997; Tansman et al., 2017). The softening result is a combination of protein hydration, demineralization of the curd, and proteolysis. These cheeses can also be manufactured using alternative practices that result in cheeses with varying paste stability and structural integrity (Batty et al., 2019). With these 2 variables, the timing of HPP treatment and bloomy rind cheese variety could influence the ripening of the cheeses and overall product quality. Calzada et al. (2014a) evaluated the impact of HPP (400 and $600 \mathrm{MPa}$ ) on Brie cheese at 14 and $21 \mathrm{~d}$ after manufacture and found a reduced rate of proteolysis and improved flavor quality at the end of shelf life.

The objective of the current study was to determine the effect of HPP treatment applied at different points in the aging process on the physical and microbiological quality of 3 different recipes of Camembert-type cheese that represent the range of physiochemical properties, ripening rate, and shelf life: (1) traditional (sweet curd) Camembert, (2) stabilized Camembert, and (3) hybrid Camembert. The traditional and stabilized recipes were obtained from producers of Camembert-type cheese and modified to work with the equipment available at the Oregon State University Creamery. The hybrid recipe was developed at Oregon State University to serve as a middle point between the 2 recipes.

\section{MATERIALS AND METHODS}

\section{Overall Experimental Design}

Three different manufacturing recipes were used to produce Camembert-type cheese. The recipes included a more traditional variety (sweet curd), a stabilized variety (stabilized), and a combination of the 2 (hybrid). Camembert-type cheese varieties were subjected to HPP at 3 time points after manufacture: 3,11 , and $45 \mathrm{~d}$. We selected these times to evaluate possible treatment points throughout ripening. The growth of $L$. monocytogenes was evaluated on the surface of Camembert-type cheese using the stabilized variety and multiple possible points of contamination during ripening. Pressure treatments were performed in duplicate at each time point, and the composition and physical and microbiological quality were monitored throughout shelf life (up to $50 \mathrm{~d}$ after manufacture). To evaluate the reduction of $L$. monocytogenes only, we used the 11-d treatment time and stabilized variety.

\section{Cheesemaking}

Camembert cheesemaking procedures followed those described by Batty et al. (2019). Pasteurized whole milk (average protein-to-fat ratio of $0.99 ; 75 \mathrm{~kg} /$ batch) was obtained from a regional fluid milk processor and transported to the Arbuthnot Dairy Center at Oregon State University (Corvallis, OR) for cheese manufacture. Milk was added to a round cheese vat (C. van't Riet Dairy Technology B.V., Nieukoop, the Netherlands) and heated to the set fermentation temperature depending on the recipe (Table 1). Depending on the recipe, a mesophilic blend (Flora Danica-DVS, Chr. Hansen Inc., Milwaukee, WI) or the thermophilic 
starter Streptococcus thermophilus (Choozit DVI TA 50 series, Danisco, Copenhagen, Denmark) was added to the cheese vat along with ripening cultures $[P$. candidum (PCA 3, Chr. Hansen Inc.; 0.40 U/100 kg), G. candidum (Choozit Geo 15 LYO, Danisco; 0.15 U/100 kg), and Kluyveromyces marxianus (LAF 4, Chr. Hansen Inc.; $0.15 \mathrm{U} / 100 \mathrm{~kg}$ )]. The quantity of starter culture used for each cheese type is shown in Table 1. Leuconostoc mesenteroides ssp. cremoris (Choozit LM 57, Danisco; $0.73 \mathrm{U} / 100 \mathrm{~kg}$ ) was also added as an adjunct culture to the stabilized variety for flavor development. Calcium chloride (DCI, 32-33\% wt/vol, Dairy Connections Inc., Madison, WI) was added to all recipes at a rate of $6.6 \mathrm{~mL} / 100 \mathrm{~kg}$ to enhance curd formation. Fermentation continued until the targeted set $\mathrm{pH}$ of each recipe was achieved (Table 1 ). The milk was then transferred to soft cheese semicylindrical coagulation basins (Servi Doryl, Langeais, France). Coagulant (DCI Star Coagulant, Dairy Connections Inc.) was added to the fermented milk at a rate of $5.3 \mathrm{~mL} / 100 \mathrm{~kg}$ and left undisturbed for 25 to $35 \mathrm{~min}$. Coagulum firmness was determined by visual assessment and by using the flocculation assessment with a multiplication factor of 5 for the traditional variety and 3 for the stabilized and hybrid varieties (Caldwell, 2012). The coagulum was cut using either 1-cm or 2-cm knives (Table 1; Servi Doryl), the curd-whey mixture was stirred 3 times over $30 \mathrm{~min}$, and the whey was drained $10 \mathrm{~min}$ after the final stir. Cheese molds $(\mathrm{n}=120 / \mathrm{vat})$ (Fromagex, Rimouski, Québec, Canada; 7-cm diameter) were filled using a curd distributor (Fromagex) to obtain an average cheese weight of $95 \pm 10 \mathrm{~g}$.

The cheeses were drained overnight at $21 \pm 1^{\circ} \mathrm{C}$ with turning at $30 \mathrm{~min}$ and 5, 10, and $19 \mathrm{~h}$. After being in the mold for 14 to $20 \mathrm{~h}$, the cheese was removed (Table 1) and dry salted ( $2 \% \mathrm{wt} / \mathrm{wt})$. The cheese was then open-air dried for an additional 1 to $2 \mathrm{~h}$. This time point marked d 0 (start of ripening) for downstream treatments and sampling time points. The cheeses were transferred to an incubator $\left(15 \pm 1^{\circ} \mathrm{C}, 85 \%\right.$ relative humidity) for $24 \mathrm{~h}$. The relative humidity was then increased to $95 \%$ and temperature decreased to $13 \pm 1^{\circ} \mathrm{C}$ for $14 \mathrm{~d}$, and the cheeses were flipped daily to encourage uniform surface mold development. The cheeses were then wrapped in white mold paper (Fromagex) and stored at $7 \pm 1^{\circ} \mathrm{C}$ for up to $50 \mathrm{~d}$ after manufacture. The wrapped cheeses were flipped weekly.

\section{Contamination and Growth of Listeria monocytogenes in Camembert}

Listeria monocytogenes Cocktail Preparation. Listeria monocytogenes strains [ScottA (serotype 4b, clinical isolate), California (serotype $4 \mathrm{~b}$, isolated from Mexican-style cheese associated with an outbreak in 1985), Ohio (serotype 4b, isolated from recalled cheese), and ATCC 19116 (serotype 4c, isolated from chicken in England)] were revived from cryogenically preserved stock cultures by being transferred to tryptic soy broth (TSB; Neogen, Lansing, MI) and incubated at $37^{\circ} \mathrm{C}$ for $24 \mathrm{~h}$. Broth cultures were streaked on CHROMagar Listeria (CHROMagar, Paris, France) to verify that selected colony were L. monocytogenes. A representative colony of each strain was selected and transferred to $\mathrm{TSB}$ and incubated at $37^{\circ} \mathrm{C}$ for $24 \mathrm{~h}$. Individual TSB cultures were spread-plated onto tryptic soy agar (TSA; Neogen) and incubated at $37^{\circ} \mathrm{C}$ for $24 \mathrm{~h}$. The resulting bacterial lawn was harvested by adding whey (obtained from the cheese make) to the TSA plate and removed using a bacterial cell spreader. Each harvested bacterial lawn was transferred to individual $50-\mathrm{mL}$ conical vials. All lawn harvests were combined in equal volumes to create a cocktail. This cocktail was serially diluted using whey to a target concentration of $\sim 3 \log$ $\mathrm{cfu} / \mathrm{mL}$ before inoculating cheese.

Cheese Inoculation with Listeria monocytogenes Cocktail. Stabilized Camembert cheeses were inoculated at 4 points in the ripening process. These 4 points included (1) immediately after removal of the cheeses from the cheese molds and before salting, (2) postsalting ( $2 \mathrm{~h}$ after salt application), (3) $5 \mathrm{~d}$ after manufacture (after the surface yeasts and molds began to grow), and (4) $10 \mathrm{~d}$ after manufacture. These 4 time points were selected to represent the different stages of

Table 1. Cheesemaking controls for each recipe of Camembert-type cheese

\begin{tabular}{lccc}
\hline Camembert variety & Sweet curd & Hybrid & Stabilized curd \\
\hline Starter type & Mesophilic & Mesophilic & Thermophilic \\
Starter quantity $(\mathrm{U} / 100 \mathrm{~L})$ & 7.6 & 7.6 & 9.7 \\
Fermentation temperature $\left({ }^{\circ} \mathrm{C}\right)$ & 35 & 6.5 & 40 \\
Set pH & 6.2 & 2 & 6.45 \\
Cut size $(\mathrm{cm})$ & 2 & 6.4 & 6.2 \\
Drain pH & 6.1 & 14 & 20 \\
Drain time $(\mathrm{h})$ & 20 & $5.1-5.2$ & $5.2-5.3$ \\
pH at salting & $4.6-4.7$ & $4.9-5.0$ & $5.2-5.3$ \\
pH on d 1 & $4.5-4.6$ & & \\
\hline
\end{tabular}


cheese ripening while the cheese is open to the environment and at risk of contamination. Each cheese was spot inoculated with $100 \mu \mathrm{L}$ of the diluted L. monocytogenes cocktail on the surface of each flat face of the cheese. Ripening conditions were resumed after inoculation, and L. monocytogenes populations were enumerated at the time of inoculation; $1 \mathrm{~d}$ after inoculation; at d 5, 11, and 25 during aging; and at the end of aging $(60 \mathrm{~d})$. Inoculation studies and reduction evaluation of L. monocytogenes were performed in duplicate $(\mathrm{n}=2)$ using 2 unique sets of prepared inocula. The cheeses treated with HPP had been inoculated on the day of salting to imitate worst-case scenario (maximum opportunity for growth to achieve high cell density).

\section{High-Pressure Processing}

The cheeses were treated with HPP at 3,11 , and 45 $\mathrm{d}$ after manufacture. For the evaluation of L. monocytogenes reduction, the cheeses were processed $11 \mathrm{~d}$ after manufacture. The cheese wheels were packaged in white mold paper, placed in 3-mil plastic pouches (UltraSource, Kansas City, MO), and sealed under light vacuum. The cheeses were shipped overnight on ice to the Cornell HPP Validation Center (Ithaca, NY) for immediate processing in a 55 -L commercial scale unit (Hiperbaric, Miami, FL). The cheeses were pressurized at $550 \mathrm{MPa}$ at $25^{\circ} \mathrm{C}$ with a hold time of $10 \mathrm{~min}$ for the quality evaluation and 350,450 , and $550 \mathrm{MPa}$ at $25^{\circ} \mathrm{C}$ with a hold time of $10 \mathrm{~min}$ for the L. monocytogenes reduction. Product temperature changes due to adiabatic heating during pressurization were expected; however, they were not monitored during HPP treatment. The cheeses were boxed and returned to Oregon State University via overnight shipping and returned to the ripening area upon arrival. All shipped cheese was returned to normal aging within $48 \mathrm{~h}$ after initial boxing. Travel controls for each set of treatments were shipped with the HPP-treated cheese and aged normally upon return to ensure transportation did not degrade the cheese quality. Controls used for quality analysis were aged normally (without shipping).

\section{Composition, Physiochemical, and Microbiological Analysis}

Milk and Cheese Composition. Milk composition (fat, protein, lactose, and solids-not-fat) was analyzed using a milk analyzer (Lacticheck-01 RapiRead, Page \& Pedersen International Ltd., Hopkinton, MA) on the day of cheese manufacture. Two samples of each cheese type were removed from ripening on d 5 for composition analysis including fat, moisture, protein, and microcomponents (Ca, Na, P). Before macrocomponent (fat, protein, and moisture) analysis, whole cheese wheel samples were homogenized by blending for $15 \mathrm{~s}$ until pieces were small and uniform. The moisture content was determined using a rapid analyzer for solids and moisture (Arizona Instrument LLC, Chandler, AZ). Fat was analyzed by the Van Gulik method (International Organization for Standardization, 2008). Total nitrogen was measured using a combustion analyzer (vario MACRO cube, Elementar Analysensysteme GmbH, Hanau, Germany). Crude protein was calculated by multiplying the total nitrogen by 6.38 . For microcomponent analysis $(\mathrm{Ca}, \mathrm{P}, \mathrm{Na}), 10$ subsamples were taken from each wheel and dried at $35^{\circ} \mathrm{C}$ for $96 \mathrm{~h}$ before grinding with a mortar and pestle. The samples (200 g) were mixed with $15 \mathrm{M}$ nitric acid $(8.0 \mathrm{~mL}$; Macron Fine Chemicals, Center Valley, PA) and 30\% hydrogen peroxide $(2.0 \mathrm{~mL})$ and held for 10 to $15 \mathrm{~min}$. Microwave digestion (Multiwave GO, Anton Paar USA, Ashland, VA) was performed at $180^{\circ} \mathrm{C}$ for $10 \mathrm{~min}$. Samples were vented and cooled for $5 \mathrm{~min}$. The acid solution was transferred to a volumetric flask and diluted to $50 \mathrm{~mL}$ using deionized water. Microcomponents were quantified using inductively coupled plasma atomic emission spectroscopy (Agilent 5110, Agilent Technologies, Santa Clara, CA) at Oregon State University's Central Analytical Laboratory.

Microbiological Analysis. The cheese samples were removed from ripening on $\mathrm{d} 7,21,35$, and 50 for enumeration of microbial populations. The cheese samples (25 g) were transferred to a sterile Whirl-Pak bag (Nasco, Salida, CA) and combined with a 1:1 ratio of $0.1 \%$ peptone water. The samples were stomached (Easymix, bioMérieux, Marcy-l'Étoile, France) for $30 \mathrm{~s}$ until homogeneous. The cheese homogenate underwent serial dilution in $0.1 \%$ peptone water, and $0.1-\mathrm{mL}$ aliquots were spread-plated on appropriate growth media. Oxytetracycline-glucose yeast extract agar (Neogen; $25^{\circ} \mathrm{C}$ for $3-5 \mathrm{~d}$ ) was used for the enumeration of yeasts and molds. Penicillium candidum was enumerated by counting only the white mold colonies on the plate. Listeria monocytogenes was enumerated by standard dilution and spread-plating methods using CHROMagar Listeria $\left(37^{\circ} \mathrm{C}\right.$ for $\left.48-72 \mathrm{~h}\right)$.

Texture Analysis. Cheese firmness was measured on d $7,14,21,35$, and 50 after manufacture using methods previously described (Abraham et al., 2007; Batty et al., 2019). The texture analyzer TAXT2i (Texture Technologies Corp., Hamilton, MA) equipped with a 5-kg load cell and a 6-mm cylindrical probe was used for penetration measurements. The cheese was held for $1 \mathrm{~h}$ at room temperature $\left(23^{\circ} \mathrm{C}\right)$ before texture analysis. During the test, the penetration speed was $0.4 \mathrm{~mm} / \mathrm{s}$ with a total penetration depth of $75 \%$ of the cheese height. Firmness of the cheese paste was recorded at 
the minimum peak and maximum peak within the paste. The paste measurements were the low and high points for firmness after the initial rind fracture peak. Texture analysis was performed on 2 cheeses of each variety at each time point.

$p H$. The $\mathrm{pH}$ was measured throughout the cheese make and ripening period using a portable meter (Portable Food and Dairy pH Meter, Hanna Instruments, Woonsocket, RI) equipped with a conical penetration probe designed for semisolid foods. Cheese rind $\mathrm{pH}$ measurements were performed in triplicate for each side. For the paste, $1 \mathrm{pH}$ measurement was taken from the center of the cheese. Two cheeses per treatment were analyzed on d 7, 14, 21, 35, and 50 after manufacture.

Color. The color of the cheese paste and rind were measured using a spectrophotometer (LabScan XE Spectrophotometer, Hunter Associates Laboratory Inc., Reston, VA). Color measurements of paste and rind were measured in triplicate for 2 cheeses per treatment on d $7,14,21,35$, and 50 after manufacture.

Data Analysis. All data analysis for these experiments was completed using JMP 13.0 (SAS Institute Inc., Cary, NC). The means, standard deviations (cheese composition), and standard errors (all other quality metrics) were calculated. The standard error was calculated for 2 replicate pressure treatments $(\mathrm{n}=$ 2). Mean comparisons were made by computing a oneway ANOVA and differences were further compared using the Tukey-Kramer honestly significant difference test.

\section{RESULTS AND DISCUSSION}

\section{Cheese Composition}

The traditional, stabilized, and hybrid Camemberttype cheese varieties differed significantly in moisture, protein, $\mathrm{Ca}$, and $\mathrm{P}$ contents at $5 \mathrm{~d}$ after manufacture $(P$ $<0.05$; Table 2). The composition results obtained were expected given the differences in the recipes that were used to produce these cheeses. These compositional differences are attributable to differences in formulations and cheesemaking practices of Camembert-type cheese (Batty et al., 2019). The lower moisture of the stabilized curd was most likely due to the smaller cut size used because less distance is needed to be covered for the whey to expel from the curd, resulting in more whey expulsion (Walstra, 1993; Guinee and O'Callaghan, 2010). The higher level of protein for the stabilized curd was likely due to the displacement of components with the different moisture contents because the protein content on a dry basis was not significantly different. All 3 of these cheeses had a Ca content that was directly related to the $\mathrm{pH}$. The stabilized variety had the highest $\mathrm{pH}$ (5.2-5.3) and Ca content and the traditional (sweet curd) variety had the lowest $\mathrm{pH}(4.6-4.7)$ at all control points (cutting, draining, and salting) leading to lowest levels of total Ca. Differences in Ca content are most likely due to differences in $\mathrm{pH}$ throughout the process, as previously stated by Lucey and Fox (1993). pH as a control of the total $\mathrm{Ca}$ and $\mathrm{P}$ or the insoluble $\mathrm{Ca}$ has been successfully used in many studies on Cheddar, mozzarella, and Camembert-type cheeses (Guinee et al., 2002; Upreti and Metzger, 2006; Batty et al., 2019). Salt content between the cheese varieties in the current study did not differ significantly.

\section{Listeria monocytogenes Growth on Camembert-Type Cheese After Surface Contamination}

Listeria monocytogenes was capable of growing on the surface of stabilized Camembert-type cheese at all inoculation points. From the initial level of contamination (2-3 log cfu/g), the concentration decreased slightly by d 5 (Figure 1). Continued ripening supported exponential growth of $L$. monocytogenes on the surface of the cheese, regardless of the timing of inoculation. By $25 \mathrm{~d}$ after manufacture, L. monocytogenes reached levels in excess of $7.4 \pm 0.2 \mathrm{cfu} / \mathrm{g}$. This high level would present a great risk to consumers and producers of Camemberttype cheese.

Listeria monocytogenes contamination occurring later in the ripening period ( $11 \mathrm{~d}$ after manufacture) was also capable of growing on Camembert-type cheese; however, the growth rate was substantially reduced as compared with contamination that occurred during production. The decreased growth rate was likely due to the cooler ripening temperature during this production stage. By the time of consumption (d 60 after manufacture), $L$. monocytogenes levels had increased to $5.6 \pm 0.5 \mathrm{cfu} / \mathrm{g}$. These results are comparable to previous studies of $L$. monocytogenes growth during aging and refrigerated storage of bloomy rind cheeses including both Camembert and Brie (D'Amico et al., 2008; Kapetanakou et al., 2017). With all contamination events resulting in high concentrations of L. monocytogenes (>5.6 log $\mathrm{cfu} / \mathrm{g})$ by the end of shelf life, applying HPP as close to distribution as possible would be ideal. Three time points in the ripening period were selected to investigate the suitability of HPP to maintain product quality and mitigate L. monocytogenes contamination and growth in bloomy rind cheeses: (1) $45 \mathrm{~d}$ after manufacture (mid shelf life and typical consumption time), (2) $11 \mathrm{~d}$ after manufacture (after the surface yeasts and molds developed and when the cheeses are wrapped), and (3) $3 \mathrm{~d}$ after manufacture (before surface yeast and mold development). 


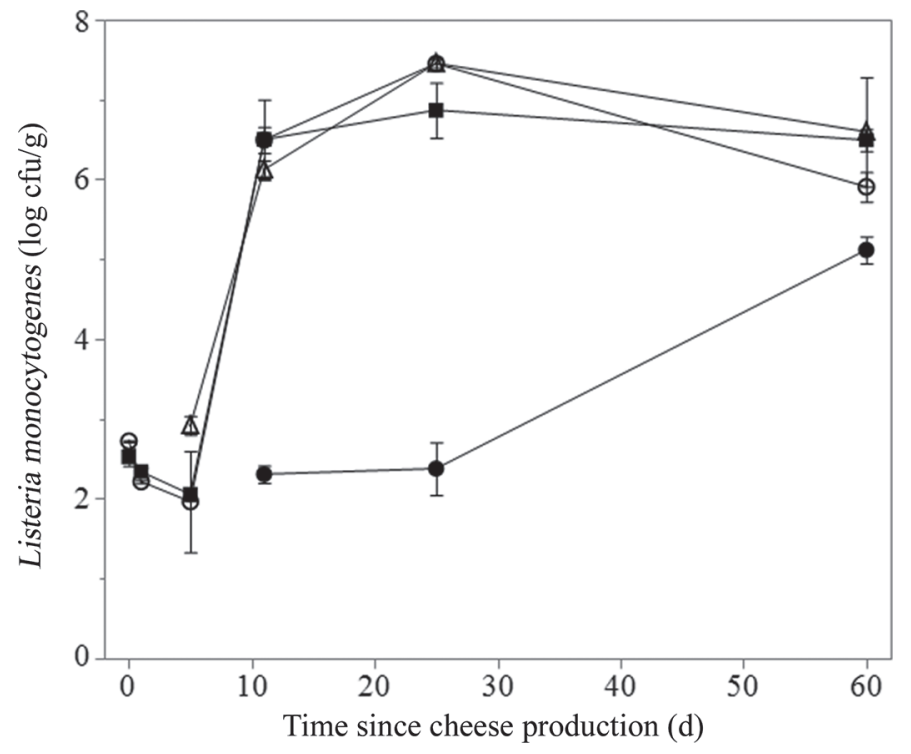

Figure 1. Growth of Listeria monocytogenes during the ripening and storage of stabilized Camembert cheese with different points of contamination. (a) Presalting contamination (d 0; O); (b) postsalting contamination ( $\mathrm{d} 0 ; \mathbf{\square})$; (c) contamination after the first surface yeasts grow $(\mathrm{d} 5 ; \Delta) ;(\mathrm{d})$ contamination at the end of open-air storage before the cheese is wrapped $(\mathrm{d} 11 ; \boldsymbol{\bullet})$. A data point is not shown on the graph until the day of contamination. Values shown are mean \pm standard deviation.

\section{Reduction of L. monocytogenes on Camembert-Type Cheese Using HPP}

Efficacy of HPP treatment against L. monocytogenes was tested at $11 \mathrm{~d}$ after manufacture only. Listeria monocytogenes was significantly reduced $(P<0.05)$ using pressures at 350,450 , and $550 \mathrm{MPa}$ compared with both controls (aging and travel). With both the 450 and $550 \mathrm{MPa}$ treatments, $>5-\log$ reduction of $L$. monocytogenes was observed (Figure 2). These results are similar to previous studies that also achieved large reductions of L. monocytogenes in queso fresco, goat cheese, and washed-curd model cheese (Gallot-Lavallee, 1998; López-Pedemonte et al., 2007; Tomasula et al., 2014). Although HPP offers great reduction potential, between 1 and $2 \mathrm{log}$ cfu/g of L. monocytogenes remains on the cheese. This amount is concerning because this level of L. monocytogenes on the surface of the cheese was achieved with low-level contamination just after manufacture. Any surviving L. monocytogenes presents a risk due to the growth potential during the remaining shelf life.

\section{HPP Treatment at Day 45}

The 45-d HPP treatment is representative of a treatment time that would minimize the food safety risk immediately before distribution of bloomy rind cheeses, especially for the products with a longer shelf life (stabilized variety). The stabilized variety has an improved shelf life due to the greater quantity of insoluble Ca allowing for slower breakdown of the internal paste of the cheese. This time point would be the optimum treatment time from a food safety stance because the risk for recontamination is extremely low and the opportunity for regrowth is limited. The cheese would also be at the ideal point for consumption and the risk would be the highest based on the L. monocytogenes growth study.

Cheese Appearance. By d 50 after manufacture, the white mycelium of the surface fungi covers the cheese

Table 2. Composition expressed as percent weight of cheese (means \pm SD) for 3 varieties of Camembert-type cheese sampled $5 \mathrm{~d}$ after manufacture

\begin{tabular}{lccc}
\hline Component & Sweet curd & Hybrid & Stabilized curd \\
\hline Moisture $^{2}{ }^{1}$ & $57.17 \pm 0.59^{\mathrm{a}}$ & $58.13 \pm 0.40^{\mathrm{a}}$ & $53.67 \pm 0.61^{\mathrm{b}}$ \\
& $23.35 \pm 0.21$ & $23.13 \pm 0.25$ & $23.90 \pm 0.35$ \\
Protein $^{1}$ & $(54.53 \pm 1.25)$ & $(55.23 \pm 1.12$ & $(51.59 \pm 1.54)$ \\
& $15.63 \pm 0.34^{\mathrm{b}}$ & $15.52 \pm 0.33^{\mathrm{b}}$ & $17.29 \pm 0.39^{\mathrm{a}}$ \\
Salt $^{2}$ & $(36.44 \pm 0.29)$ & $(37.05 \pm 0.43)$ & $(37.31 \pm 0.36)$ \\
Salt-in-moisture (S/M) $^{2}$ & $1.52 \pm 0.13$ & $1.65 \pm 0.17$ & $1.63 \pm 0.16$ \\
$\mathrm{Na}^{1}$ & $2.67 \pm 0.25$ & $2.85 \pm 0.32$ & $3.06 \pm 0.37$ \\
& $0.60 \pm 0.05$ & $0.65 \pm 0.07$ & $0.64 \pm 0.06$ \\
$\mathrm{Ca}^{1}$ & $(1.41 \pm 0.10)$ & $(1.56 \pm 0.15)$ & $(1.39 \pm 0.12)$ \\
$\mathrm{P}^{1}$ & $0.35 \pm 0.02^{\mathrm{b}}$ & $0.39 \pm 0.03^{\mathrm{ab}}$ & $0.47 \pm 0.07^{\mathrm{a}}$ \\
& $\left(0.78 \pm 0.04^{\mathrm{b}}\right)$ & $\left(0.94 \pm 0.06^{\mathrm{ab}}\right)$ & $\left(1.01 \pm 0.16^{\mathrm{a}}\right)$ \\
& $0.27 \pm 0.03^{\mathrm{b}}$ & $0.28 \pm 0.02^{\mathrm{ab}}$ & $0.36 \pm 0.02^{\mathrm{a}}$ \\
& $\left(0.62 \pm 0.06^{\mathrm{b}}\right)$ & $\left(0.67 \pm 0.06^{\mathrm{ab}}\right)$ & $\left(0.86 \pm 0.04^{\mathrm{a}}\right)$ \\
\hline
\end{tabular}

$\overline{\mathrm{a}, \mathrm{b}}$ Cheese composition values within a row that do not share the same superscript are significantly different $(P<0.05)$.

${ }^{1}$ Values in parentheses indicate component percentage on dry basis.

${ }^{2}$ Calculated values including salt $(\mathrm{Na} \times 2.54) ; \mathrm{S} / \mathrm{M}[($ salt $\% \times 100) \div$ moisture $\%]$; percent "as-is" protein and minerals $(\mathrm{Na}, \mathrm{Ca}, \mathrm{P})$ [attribute $\times($ moisture \%/100)]; percent fat "dry basis" [attribute/(100 - moisture \%) $\times 100]$. 


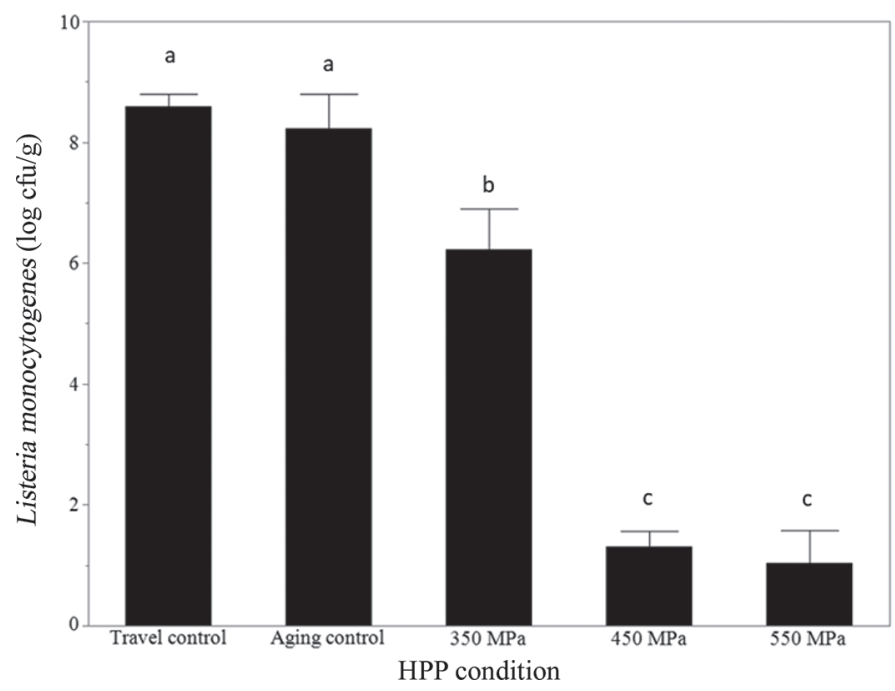

Figure 2. Reduction of Listeria monocytogenes on Camemberttype cheese treated with high-pressure processing (HPP) at 350, 450, and $550 \mathrm{MPa}$ at $11 \mathrm{~d}$ after manufacture. Travel control samples were shipped along with HPP-treated samples. Aging control samples were maintained in the aging environment while HPP-treated and travel controls were shipped. Significant differences of the means are indicated by letters $(\mathrm{a}-\mathrm{c})$ above the error bars $(P<0.05)$. Error bars represent the standard error of the mean for duplicate treatments $(n=2)$.

wheel with an appearance that would satisfy typical consumer expectations. The 45-d HPP treatment negative affected the visual appearance of the cheese (Figure 3b, 3d, 3f), particularly with regard to shape deformation and discoloration of the rind. Deformation of the cheese wheel was the most severe in traditional and hybrid varieties and included fracturing of the rind, which allowed the paste to escape the wheel. The deformation in these varieties may have been caused by their higher moisture content and lower $\mathrm{Ca}$ and $\mathrm{P}$ content compared with the stabilized cheese. It has been well demonstrated that cheeses of higher moisture tend to be less firm, leaving them more susceptible to physical modification. In addition, the level of total Ca can be indicative of the softness and flowability of Camembert-type cheese (Batty et al., 2019). The HPP treatment at d 45 significantly affected the surface color of the cheese. The $\mathrm{L}^{*}$ value (measuring lightness to darkness) was significantly $(P<0.05)$ reduced (average from 13.3 to 42.4) for all varieties with this treatment (Figure 3g). This decrease indicates browning of the rind as shown in Figure $3 \mathrm{~b}, 3 \mathrm{~d}$, and $3 \mathrm{f}$. The $\mathrm{a}^{*}$ value significantly increased, from 2.39 to 6.69 , in comparisons of the control and the 45-d HPP treatment for all varieties (Figure 3). This observed increase in the $\mathrm{a}^{*}$ value indicates that the rind was becoming more red in color, which also contributed to the overall brown appearance. The $b^{*}$ value significantly increased for all varieties at the 45-d HPP treatment, with an average increase being from 14.91 to 16.53 , indicating the rind is becoming more yellow. The color change induced by HPP was also noted by Calzada et al. (2014b) in Brie cheese wedges treated with HPP at 14 and $21 \mathrm{~d}$ after manufacture, but its significance to consumer acceptance was downplayed. Voigt et al. (2010) also noted that HPP treatment significantly affected the $\mathrm{L}^{*}$ and $\mathrm{a}^{*}$ values of blue cheese.

Microbiology. The observed color change for the 45-d treatment was probably due to the destruction of $P$. candidum mycelium, as demonstrated by the observed significant reductions in yeast and mold count $(P<0.05)$. The control group for the traditional and hybrid varieties had levels of 5.5 and $6.5 \mathrm{log} \mathrm{cfu} / \mathrm{g}$, respectively, and these levels were reduced to below the limit of detection $(1 \mathrm{cfu} / \mathrm{g}$ ) after the HPP treatment. Surviving mold was detected after HPP treatment of the stabilized cheese variety $(1.2 \log \mathrm{cfu} / \mathrm{g})$, indicating that matrix composition may slightly influence mold resistance to HPP. Reductions of $P$. camemberti ( $>6$ log $\mathrm{cfu} / \mathrm{g}$ ) on Brie-type cheese subjected HPP were previously reported by Calzada et al. (2014a).

Texture and $p H$. The HPP treatment at $45 \mathrm{~d}$ had no significant effect on the firmness or $\mathrm{pH}$ of any of the cheese varieties. The average $\mathrm{pH}$ of the rind and the paste for all treated and untreated cheeses was between pH 7 and 8. After $45 \mathrm{~d}$ of aging, the $\mathrm{pH}$ of the cheeses had reached an equilibrium that was unchanged by HPP treatment. The firmness at $50 \mathrm{~d}$ for all treatments and controls was between 0.41 and $1.14 \mathrm{~N}$. Almost all the cheeses treated with HPP at $45 \mathrm{~d}$ had a less firm paste compared with their untreated controls. The average decrease in firmness was $0.45 \mathrm{~N}$ for the traditional variety, $0.21 \mathrm{~N}$ for the hybrid variety, and $0.19 \mathrm{~N}$ for the stabilized variety. However, the differences between the treatment and control of each cheese variety were not significant $(P>0.05)$. All cheeses were very soft at this stage of aging. For the traditional (sweet curd) variety, this time point would be near the end of shelf life, while for the stabilized variety, it would be near the beginning of its ideal consumption time (Batty et al., 2019).

\section{HPP Treatment at Day 11}

Due to the unacceptable quality of HPP-treated cheese at d 45, HPP treatment at d 11 was evaluated. HPP treatment at d 11 would be suitable because the surface fungi would have developed and the cheeses would be wrapped for final aging. After this wrapping is complete, the risk for contamination by L. monocytogenes and other environmental contaminants is significantly reduced.

Cheese Appearance. Visual changes of cheeses with and without HPP treatment at $11 \mathrm{~d}$ are shown 
a) Traditional control (d 50)

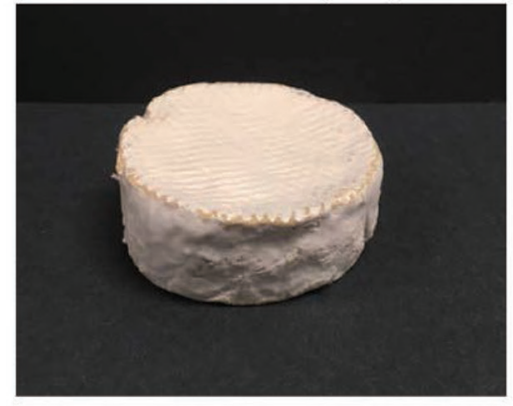

c) Hybrid control (d 50)

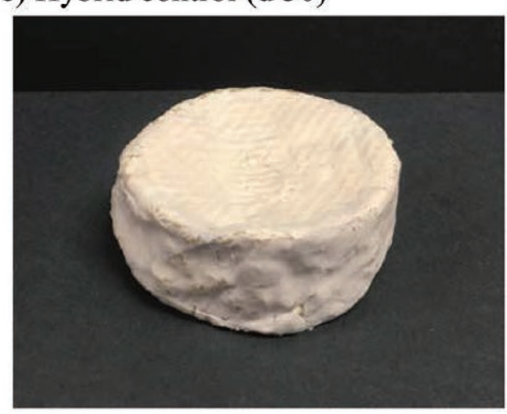

e) Stabilized control (d 50)

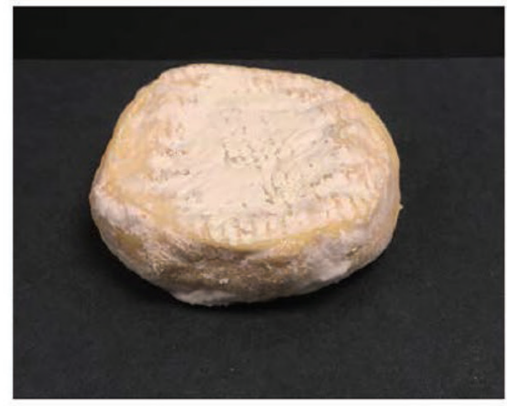

b) Traditional HPP treated (d 50)

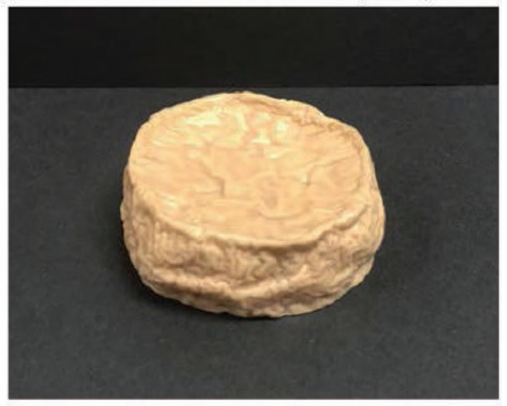

d) Hybrid HPP treated (d 50)

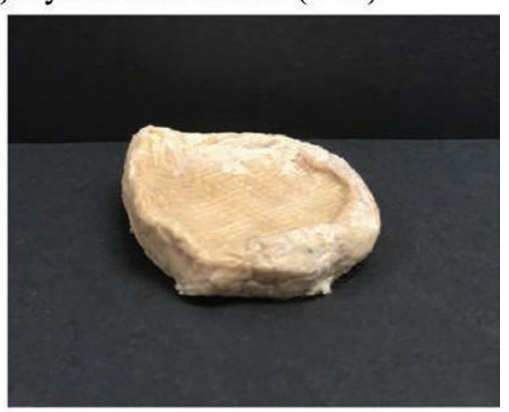

f) Stabilized HPP treated (d 50)

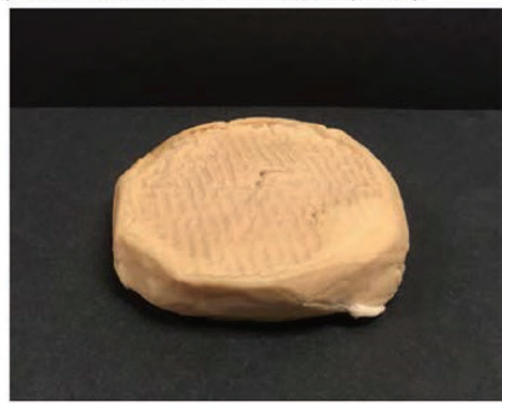

g)

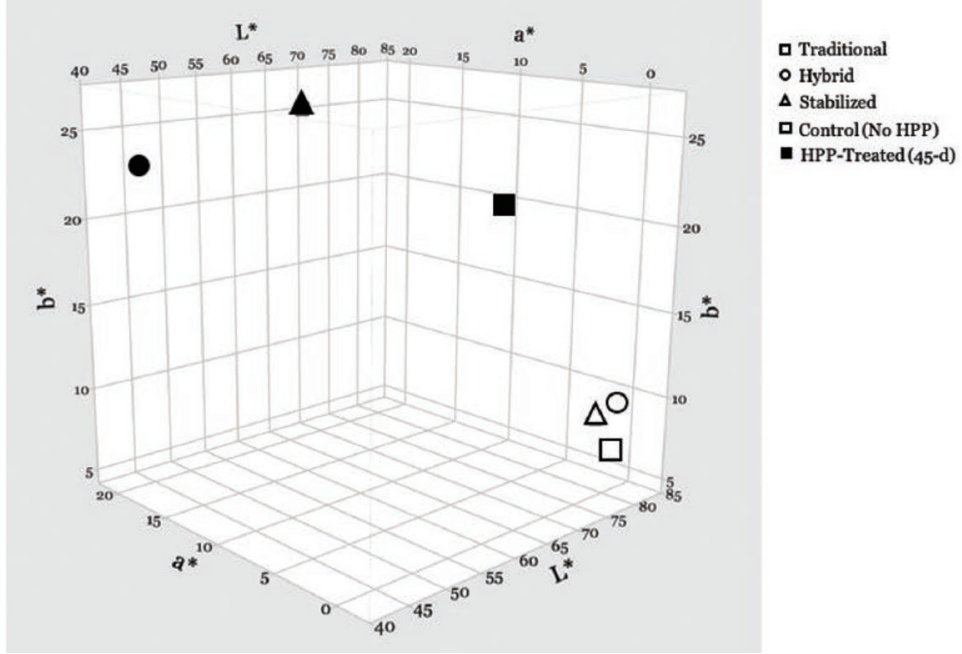

Figure 3. Cheese appearance from the 45-d high-pressure processing (HPP) treatment. The photographs were taken $50 \mathrm{~d}$ after manufacture. (a) Traditional (sweet curd) variety untreated control; (b) traditional (sweet curd) variety 45-d treatment; (c) hybrid variety untreated control; (d) hybrid variety 45-d treatment; (e) stabilized variety untreated control; (f) stabilized variety 45-d treatment; (g) color spectrum (L*, a*, and $\mathrm{b}^{*}$; lightness, red-green color and blue-yellow color, respectively) comparing the mean values for the HPP-treated and control cheese. 
in Figure 4a. Similar to the HPP treatment at $45 \mathrm{~d}$, the color of the cheese was significantly affected due to the destruction of the surface fungal mycelium. Despite continued aging, the fungus was unable to recover to repopulate the rind of any of the Camembert varieties, indicating complete destruction of the mycelium by HPP treatment (Figure $4 \mathrm{~b}-4 \mathrm{~d}$ ). The $\mathrm{b}^{*}$ significantly increased $(P<0.05)$ due to HPP treatment (Figure 5). The $\mathrm{b}^{*}$ value of the HPP-treated cheeses also increased throughout ripening, indicating that the rind was becoming more yellow over time. The $\mathrm{L}^{*}$ value decreased for the 11-d treatment compared with the control, but for most sample times and varieties, this decrease was not significant $(P>0.05)$. No apparent change in the $a^{*}$ value occurred due to HPP treatment. Application of HPP treatment at $11 \mathrm{~d}$ confirmed that the appearance of the cheese was negatively affected and that continued aging was unsuccessful at improving color

a) Traditional variety control (left), travel control (middle), HPP treated (right; d 11)

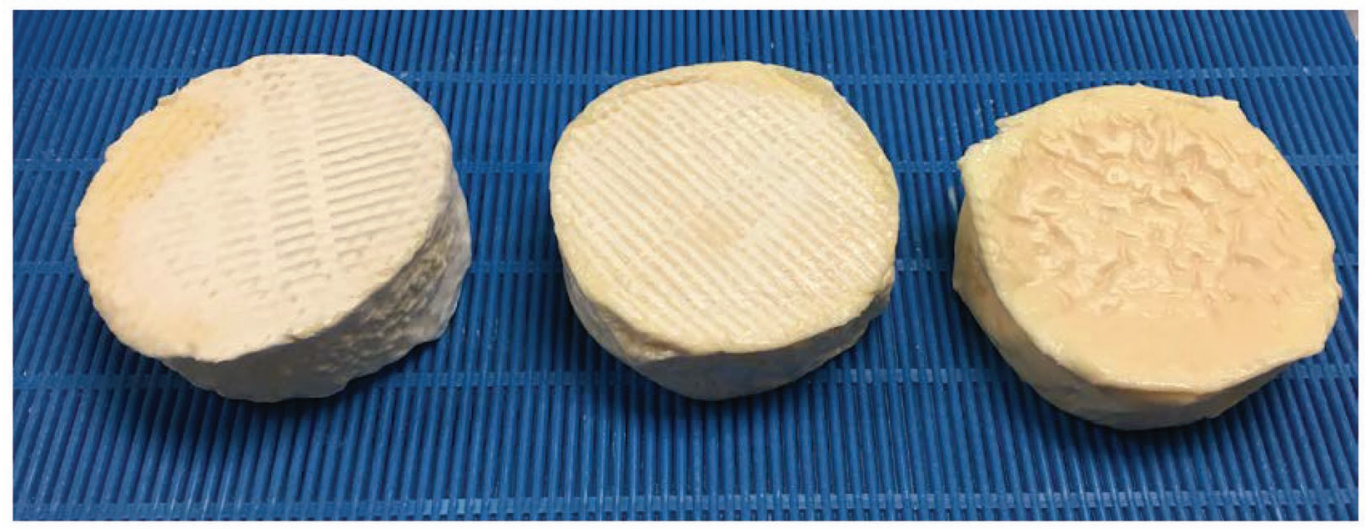

b) Traditional 11-d HPP treated (d 50)

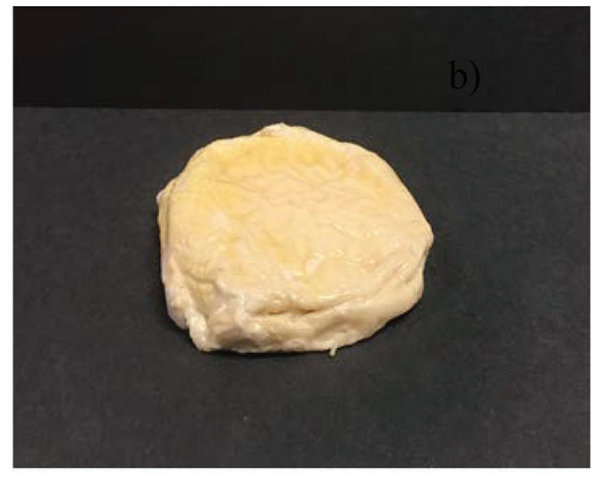

d) Stabilized 11-d HPP treated (d 50)

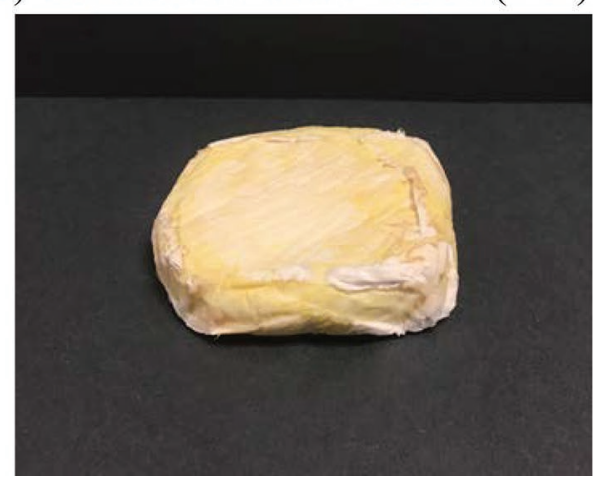

c) Hybrid 11-d HPP treated (d 50)

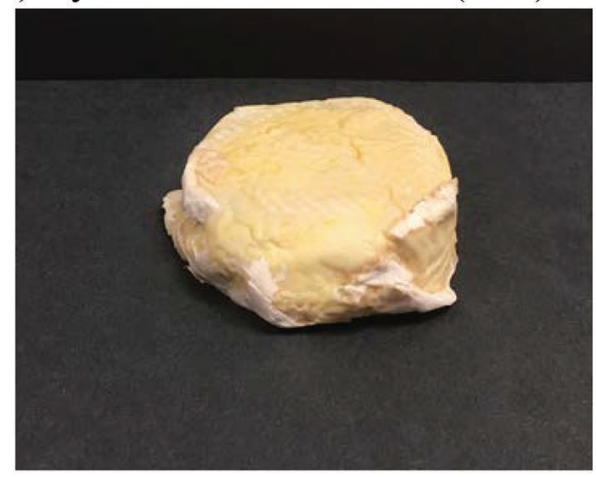

Figure 4. Cheese appearance from the 11-d high-pressure processing (HPP) treatment. Photograph (a) was taken immediately after return of 11-d treatment cheeses; photographs (b) through (d) were taken at $50 \mathrm{~d}$ after manufacture. (a) Traditional (sweet curd) variety within 24 $\mathrm{h}$ of treatment; (b) traditional (sweet curd) variety, 11-d treatment; (c) hybrid variety, 11-d treatment; (d) stabilized variety, 11-d treatment. 
quality (Figure 4). In addition to the obvious visual changes, the HPP-treated cheeses also had an obvious fruity/fermented aroma.

Microbiology. Mold counts for 11-d HPP-treated cheese were significantly lower $(P<0.05)$ than those of the control. Initial yeast and mold counts after HPP were reduced to 1.7 to $2.7 \mathrm{log} \mathrm{cfu} / \mathrm{g}$. The mold did begin to recover after HPP to 2.8 to $5.0 \mathrm{log} \mathrm{cfu} / \mathrm{g}$ by the 21-d sampling point; however, the mycelium failed to develop by the end of ripening and never achieved the expected appearance of a fully ripened Camemberttype cheese. Although HPP did not result in complete destruction of the $P$. candidum, it still negatively affected the overall appearance of the cheese.

Texture and $p \boldsymbol{H}$. Applying HPP treatment at d 11 caused a significant increase $(P<0.05)$ in the firmness of the hybrid and traditional varieties of Camembert cheese (Figure 6), whereas it had no effect on the firmness of the stabilized variety. This increase in firmness was possibly due to free serum (up to $5 \mathrm{~mL}$ ) being pressed from the cheese during the HPP treatment. Sandra et al. (2004) also observed an initial increase in firmness after the HPP treatment of queso fresco at 400 MPa for 20 min. Firmness between HPP-treated and untreated cheeses had no significant differences $(P>$ 0.05 ) for any of the varieties at the end of aging (d 50).

The development of $\mathrm{pH}$ on the surface of the cheese was significantly $(P<0.05)$ affected by the pressure

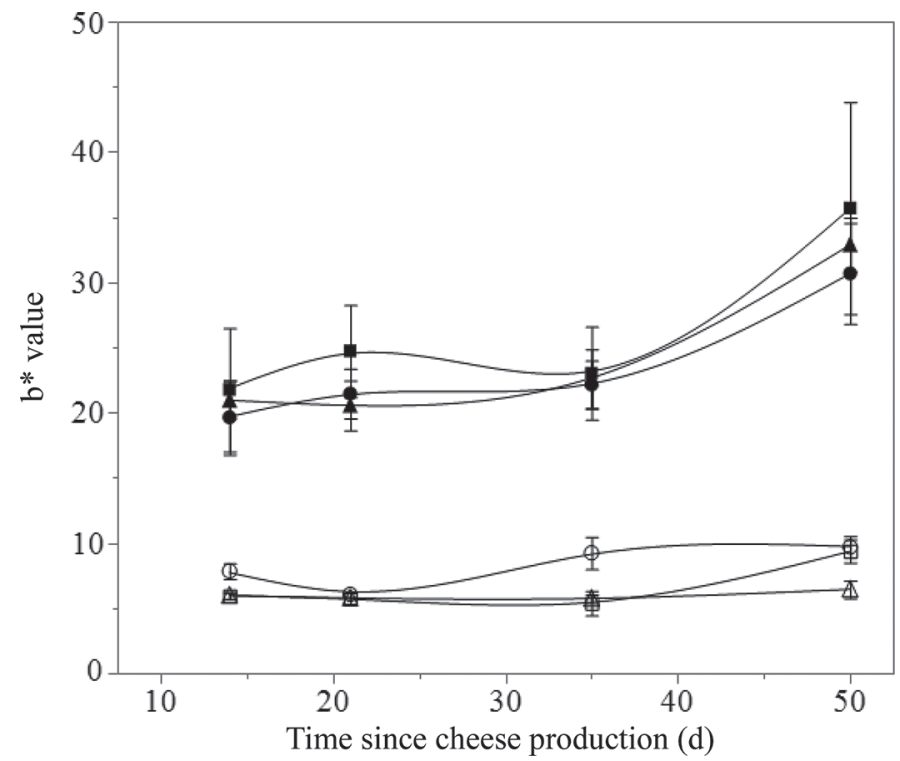

Figure 5. Blue-yellow color (b* value) of the 11-d treatment through shelf life. (a) Sweet curd (traditional) variety control $(\triangle)$; (b) sweet curd (traditional) variety high-pressure processing (HPP)

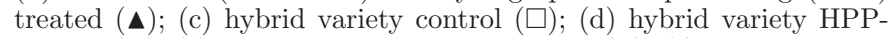
treated (ם); (e) stabilized curd variety control $(\mathrm{O})$; (f) stabilized curd variety HPP-treated $(\bullet)$. Error bars represent the standard error of the mean for duplicate treatments $(\mathrm{n}=2)$. treatment. The average surface $\mathrm{pH}$ of untreated cheese was $8.13 \pm 0.13$, whereas the HPP-treated cheeses had an average $\mathrm{pH}$ of $6.26 \pm 0.34$ (d 50 after manufacture). The increase in paste $\mathrm{pH}$ during ripening also lagged for the HPP-treated cheeses. The lower $\mathrm{pH}$ at the surface, compared with the control cheeses, was most plausibly caused by the reduction of the surface fungi because they are responsible for the $\mathrm{pH}$ increase during ripening due to proteolysis and lactate consumption (Schlesser et al., 1992; Spinnler, 2017). This observation of a delayed $\mathrm{pH}$ increase was consistent with previous findings using HPP to treat Brie cheese (Calzada et al., 2014a).

\section{HPP Treatment at Day 3}

HPP treatment at d 45 and d 11 were unsuccessful in retaining cheese quality, especially due to the color degradation associated with fungal destruction. Applying HPP treatment before mycelium development could reduce the likelihood of these color changes; however, HPP at this time point is not ideal because the cheeses would likely have additional environmental exposure during open-air ripening and further handling.

Cheese Appearance. Initially, the HPP treatment on d 3 had minimal impact on the cheese appearance, with only slight deformation of the cheese wheel (Figure 7a). With continued ripening, however, it became apparent that this treatment reduced the rate at which

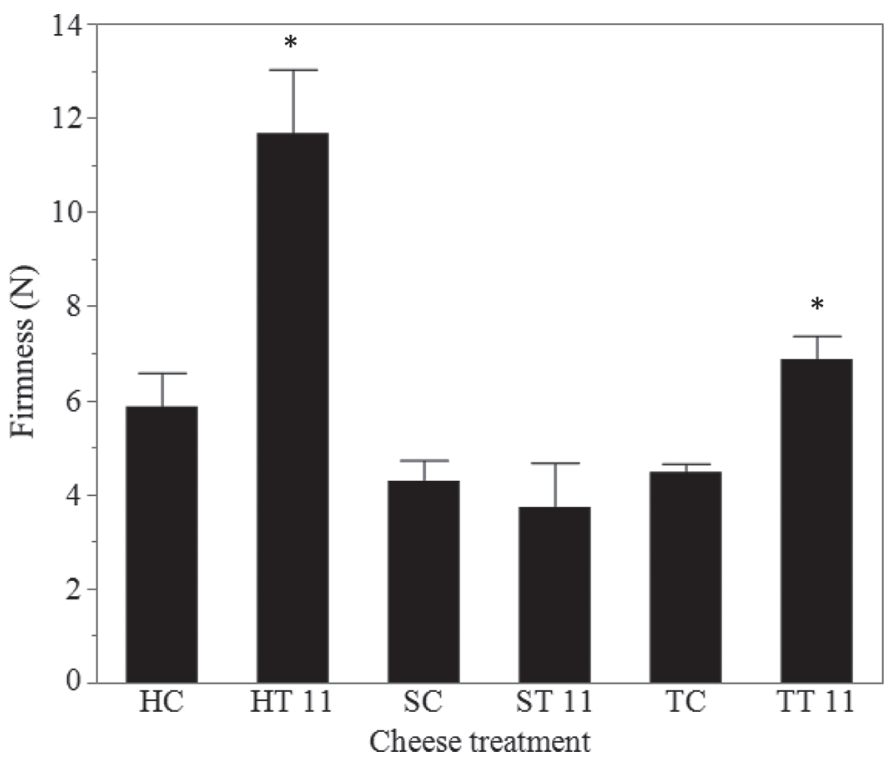

Figure 6. Firmness of the cheese from the 11-d treatment on the d-14 sample point. ${ }^{*}$ The treatment is significantly different from the control $(P<0.05)$. Error bars represent the standard error of the mean for duplicate treatments $(\mathrm{n}=2)$. $\mathrm{H}=$ hybrid; $\mathrm{S}=$ stabilized; $\mathrm{T}$ $=$ traditional; $\mathrm{C}=$ control; $\mathrm{T} 11=\mathrm{HPP}$ treated at 11 days. 
surface fungi were developing. By d 50, the surface fungi were obviously developing (Figure 7b, 7c; Figure 8); however, the development was insufficient to meet consumer expectations. Applying HPP treatment on d 3 had a significant effect on cheese color, with the greatest change in the $\mathrm{b}^{*}$ value $(P<0.05)$, indicating a yellowing of the cheese as shown in the pictures (Figure $7 \mathrm{~b}-7 \mathrm{~d})$.

Microbiology. The surface fungi, specifically $P$. candidum, were significantly $(P<0.05)$ affected by the HPP treatment (Figure 8). This reduction delayed the visible development of the surface fungal mycelium (Figure 7b-7d); however, enumerated levels of P. candidum were comparable to the control by d 21 to 35 .

Texture and $p H$. The firmness of the cheese was significantly increased $(P<0.05)$ for all varieties, with the average increase ranging from 3.07 to $8.29 \mathrm{~N}$. This initial increase was likely caused by the cheese being pressed and free serum being released $(>5 \mathrm{~mL}$ per cheese wheel). Higher firmness of HPP-treated cheeses

a) Traditional variety control (left), travel control (middle), HPP treated (right; d 3)

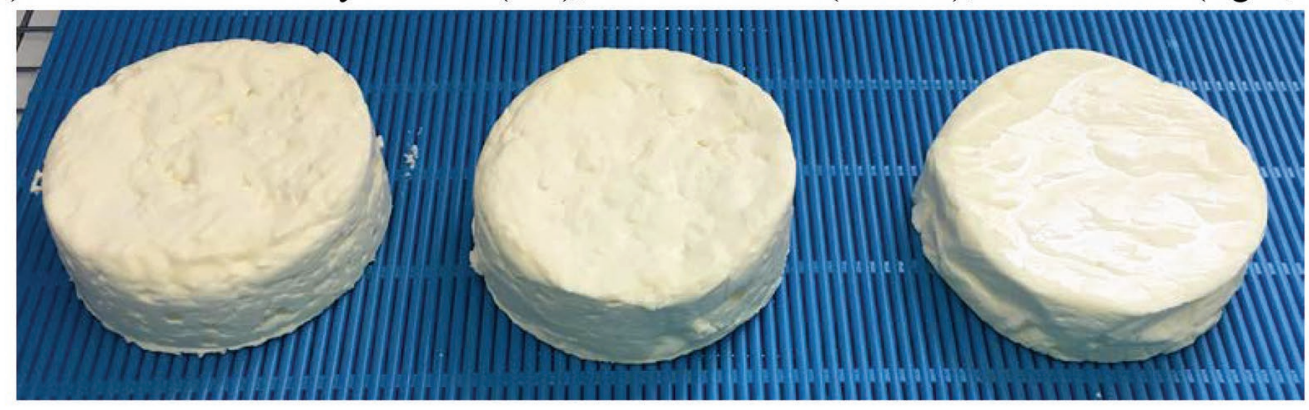

b) Traditional 3-d HPP treated (d 50)

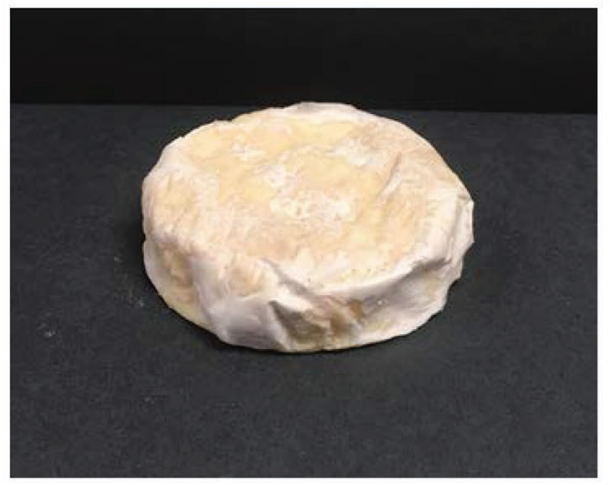

d) Stabilized 3-d HPP treated (d 50)

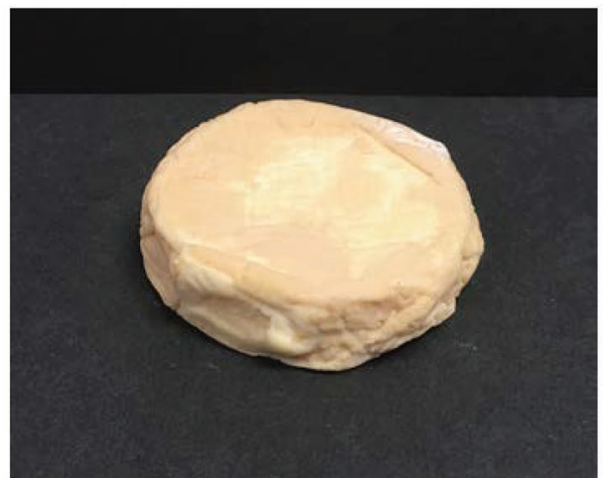

c) Hybrid 3-d HPP treated (d 50)

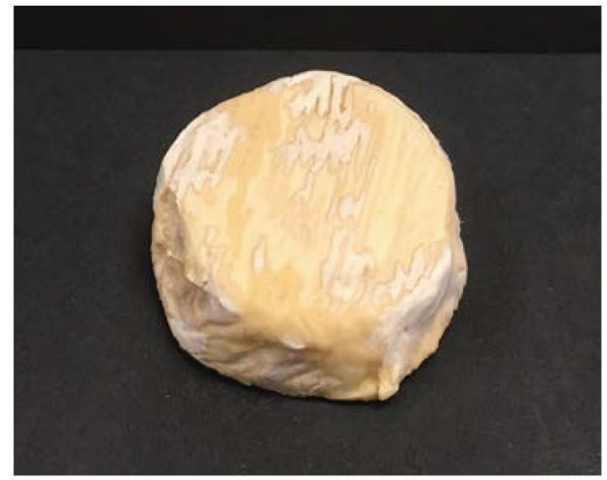

Figure 7. Cheese appearance from the 3-d high-pressure processing (HPP) treatment. (a) Traditional variety Camembert-type cheese on d 3 with and without HPP treatment. (b) Traditional variety on d 50 after HPP treatment on d 3 . (c) Hybrid variety on d 50 after HPP treatment on d 3. (d) Stabilized variety on d 50 after HPP on d 3. 


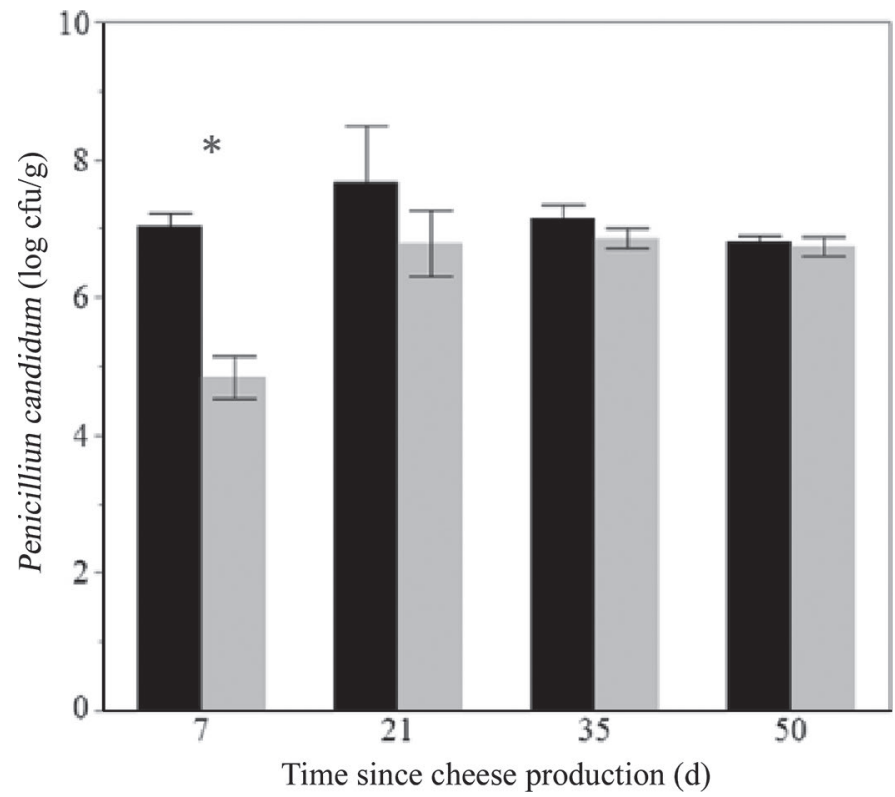

Figure 8. The counts of Penicillium candidum from the 3-d treatment through $50 \mathrm{~d}$ for the sweet curd (traditional) variety. The control is represented by the black bars and treatment by the gray bars. Error bars represent the standard error of the mean for duplicate treatments $(\mathrm{n}=2) .{ }^{*} P<0.05$ : significant difference between control and treatment.

was measured throughout shelf life; however, firmness did decrease over time.

The development of $\mathrm{pH}$ on the cheese surface was significantly influenced $(P<0.05)$ by the HPP treatment on $\mathrm{d} 3$ (Figure 9 ). This reduced rate of $\mathrm{pH}$ increase on the surface was probably because of the reduced growth of the surface fungi as previously described. This reduced rate of $\mathrm{pH}$ development could potentially slow the rate of cheese ripening and texture development, although these effects were not observed in the current study.

\section{CONCLUSIONS}

Using HPP treatment (550 MPa, $10 \mathrm{~min}$, and $25^{\circ} \mathrm{C}$ ) for Camembert-type cheese leads to unacceptable deterioration in product quality regardless of when the treatment is applied during the ripening and aging process. The primary defect in HPP-treated cheese was the destruction of the mycelium on the surface of the cheese, leading to an undesirable appearance. Until an alternative processing treatment can be identified to reduce L. monocytogenes in bloomy rind cheeses, pasteurization of the milk before cheese manufacture, sanitation, and environmental monitoring remain the only means of controlling the risk of $L$. monocytogenes infection associated with these products.

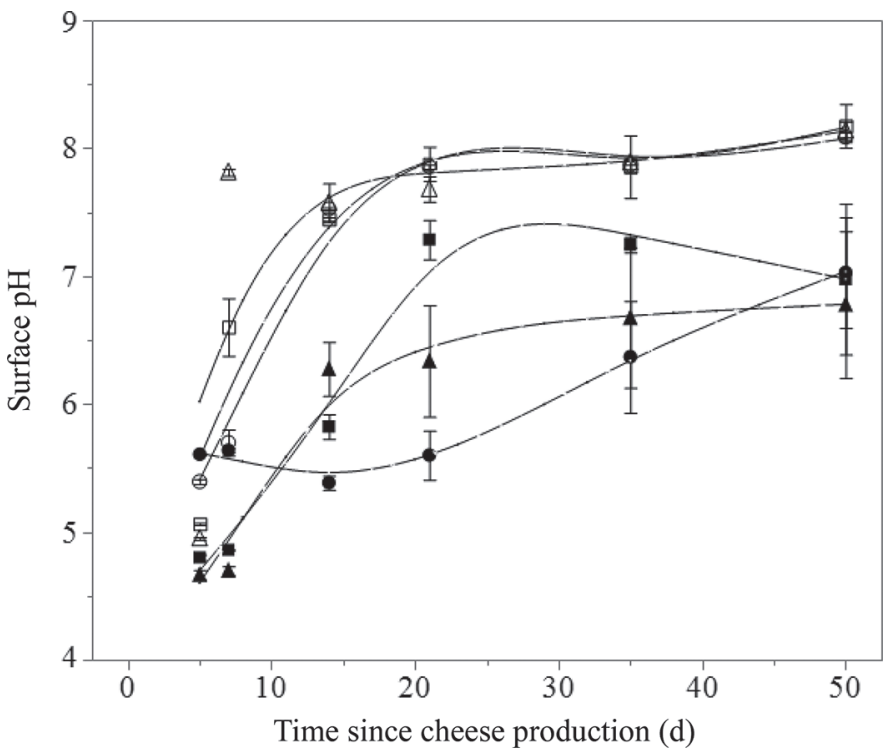

Figure 9. Surface $\mathrm{pH}$ development for the 3-d treated cheeses through 50 d. (a) Sweet curd (traditional) variety control $(\Delta)$; (b) sweet curd (traditional) variety high-pressure processing (HPP) treated (ム); (c) hybrid variety control ( $\square$ ); (d) hybrid variety HPP treated (ם); (e) stabilized curd variety control (O); (f) stabilized curd variety HPP treated $(\bullet)$. Error bars represent the standard error of the mean for duplicate treatments $(\mathrm{n}=2)$.

\section{ACKNOWLEDGMENTS}

This study was funded by Dairy Management Inc. (Rosemont, IL) and the Charles E. and Clara Marie Eckelman graduate fellowship. We thank all who helped either directly or indirectly with the completion of this study. We very much appreciate the assistance with cheesemaking and laboratory analyses provided by the staff and students of the Oregon State University (OSU) Arbuthnot Dairy Center, especially Robin Frojen and Danica Berry. We also thank Yanyun Zhao and her staff and students for supporting data collection and analysis for color and texture measurements. Alex Emch of the OSU Food Safety Systems Laboratory was critical in supporting the microbial challenge studies.

\section{REFERENCES}

Abraham, S., R. Cachon, B. Colas, G. Feron, and J. De Coninck. 2007. Eh and $\mathrm{pH}$ gradients in Camembert cheese during ripening: Measurements using microelectrodes and correlations with texture. Int. Dairy J. 17:954-960. https://doi.org/10.1016/j.idairyj 2006.12.010

Batty, D., J. G. Waite-Cusic, and L. Meunier-Goddik. 2019. Influence of cheese making recipes on the composition and characteristics of Camembert type cheese. J. Dairy Sci. 102:164-176. https://doi .org $/ 10.3168 /$ jds. 2018-14964.

Caldwell, G. 2012. Mastering Artisan Cheesemaking. Chelsea Green Publishing, White River Junction, VT. 
Calzada, J., A. Del Olmo, A. Picon, P. Gaya, and M. Nuñez. 2014a. Effect of high-pressure-processing on the microbiology, proteolysis, texture and flavour of Brie cheese during ripening and refrigerated storage. Int. Dairy J. 37:64-73. https://doi.org/10.1016/j.idairyj 2014.03.002.

Calzada, J., A. del Olmo, A. Picon, and M. Nuñez. 2014b. Effect of high-pressure-processing on lipolysis and volatile compounds of Brie cheese during ripening and refrigerated storage. Int. Dairy J. 39:232-239. https://doi.org/10.1016/j.idairyj.2014.07.007.

CDC (Centers for Disease Control and Prevention) and Health Canada. 2015. Joint FDA / Health Canada Quantitative Assessment of the Risk of Listeriosis from Soft-Ripened Cheese Consumption in the United States and Canada: Draft Report. https://www.fda.gov/ downloads/Food/FoodScienceResearch/RiskSafetyAssessment/ UCM429419.pdf.

Choi, K. H., H. Lee, S. Lee, S. Kim, and Y. Yoon. 2016. Cheese microbial risk assessments-A review. Asian-Australas. J. Anim. Sci. https://doi.org/10.5713/ajas.15.0332.

D'Amico, D. J., M. J. Druart, and C. W. Donnelly. 2008. 60-Day aging requirement does not ensure safety of surface-mold-ripened soft cheeses manufactured from raw or pasteurized milk when Listeria monocytogenes is introduced as a postprocessing contaminant. J. Food Prot. 71:1563-1571.

Evert-Arriagada, K., A. J. Trujillo, G. G. Amador-Espejo, and M. M. Hernández-Herrero. 2018. High pressure processing effect on different Listeria spp. in a commercial starter-free fresh cheese. Food Microbiol. 76:481-486. https://doi.org/10.1016/j.fm.2018.07.012.

Galli, B. D., J. G. P. Martin, P. P. M. da Silva, E. Porto, and M. H. F. Spoto. 2016. Sensory quality of Camembert-type cheese: Relationship between starter cultures and ripening molds. Int. J. Food Microbiol. 234:71-75. https://doi.org/10.1016/j.ijfoodmicro.2016 .06 .025 .

Gallot-Lavallee, T. 1998. Efficiency of high pressure treatment for destruction of Listeria monocytogenes in goat cheese from raw milk. Sci. Aliments 18:647-655.

Gripon, J. C. 1997. Flavour and Texture in Soft Cheese. 2nd ed. B. A. Law, ed. Springer Science \& Business Media, Boston, MA.

Guinee, T. P., E. P. Feeney, M. A. Auty, and P. F. Fox. 2002. Effect of $\mathrm{pH}$ and calcium concentration on some textural and functional properties of mozzarella cheese. J. Dairy Sci. 85:1655-1669. https: //doi.org/10.3168/jds.S0022-0302(02)74238-0.

ISO (International Organization for Standardization). 2008. CheeseDetermination of fat content-Van Gulik method. ISO 3433.IDF 222. ISO, Geneva, Switzerland.

Kapetanakou, A. E., M. A. Gkerekou, E. S. Vitzilaiou, and P. N. Skandamis. 2017. Assessing the capacity of growth, survival, and acid adaptive response of Listeria monocytogenes during storage of various cheeses and subsequent simulated gastric digestion. Int. J. Food Microbiol. 246:50-63. https://doi.org/10.1016/j.ijfoodmicro 2017.01.015.

Leclercq-Perlat, M.-N. 2011. Camembert, Brie, and related varieties. Pages 773-782 in Encyclopedia of Dairy Sciences. J. W. Fuquay, P. L. H. McSweeney, and P. F. Fox, ed. Academic Press, Cambridge, MA. https://doi.org/10.1016/B978-0-12-374407-4.00091-1.

López-Pedemonte, T., A. Roig-Sagués, S. De Lamo, M. HernándezHerrero, and B. Guamis. 2007. Reduction of counts of Listeria monocytogenes in cheese by means of high hydrostatic pressure.
Food Microbiol. 24:59-66. https://doi.org/10.1016/j.fm.2006.03 .008 .

Lucey, J. A., and P. F. Fox. 1993. Importance of calcium and phosphate in cheese manufacture: A review. J. Dairy Sci. 76:1714-1724. https://doi.org/10.3168/jds.S0022-0302(93)77504-9.

Muhterem-Uyar, M., M. Dalmasso, A. S. Bolocan, M. Hernandez, A. E. Kapetanakou, T. Kuchta, S. G. Manios, B. Melero, J. Minarovičová, A. I. Nicolau, J. Rovira, P. N. Skandamis, K. Jordan, D. Rodríguez-Lázaro, B. Stessl, and M. Wagner. 2015. Environmental sampling for Listeria monocytogenes control in food processing facilities reveals three contamination scenarios. Food Control 51:94-107. https://doi.org/10.1016/j.foodcont.2014.10 .042 .

Ryser, E. T., and E. H. Marth. 1987. Fate of Listeria monocytogenes during the manufacture and ripening of Camembert cheese. J. Food Prot. 50:372-378. https://doi.org/10.4315/0362-028X-50.5 .372 .

Sandra, S., M. A. Stanford, and L. M. Goddik. 2004. The use of highpressure processing in the production of queso fresco cheese. J. Food Sci. 69:153-158. https://doi.org/10.1111/j.1365-2621.2004 .tb06340.x

Schlesser, J. E., S. J. Schmidt, and R. Speckman. 1992. Characterization of chemical and physical changes in Camembert cheese during ripening. J. Dairy Sci. 75:1753-1760. https://doi.org/10.3168/jds .S0022-0302(92)77934-X.

Shaw, M. B. 1981. The manufacture of soft, surface mould, ripened cheese in France with particular reference to Camembert. Int. J. Dairy Technol. 34:131-138.

Spinnler, H. 2017. Surface mold-ripened cheeses. Pages 911-928 in Cheese: Chemistry, Physics and Microbiology. 4th ed. P. L. H. McSweeney, P. F. Fox, P. D. Cotter, and D. W. Everett, ed. Academic Press, Cambridge, MA. https://doi.org/10.1016/B978-0-12 -417012-4/00036-3.

Tansman, G. F., P. S. Kindstedt, and J. M. Hughes. 2017. Crystallization and demineralization phenomena in stabilized white mold cheese. J. Dairy Sci. 100:6074-6083. https://doi.org/10.3168/jds .2016-12259.

Tomasula, P. M., J. A. Renye, D. L. Van Hekken, M. H. Tunick, R. Kwoczak, M. Toht, L. N. Leggett, J. B. Luchansky, A. C. PortoFett, and J. G. Phillips. 2014. Effect of high-pressure processing on reduction of Listeria monocytogenes in packaged queso fresco. J. Dairy Sci. 97:1281-1295. https://doi.org/10.3168/jds.2013-7538.

Upreti, P., and L. E. Metzger. 2006. Influence of calcium and phosphorus, lactose, and salt-to-moisture ratio on Cheddar cheese quality: Manufacture and composition. J. Dairy Sci. 89:420-428. https:// doi.org/10.3168/jds.S0022-0302(06)72106-3.

Voigt, D. D., F. Chevalier, M. C. Qian, and A. L. Kelly. 2010. Effect of high-pressure treatment on microbiology, proteolysis, lipolysis and levels of flavour compounds in mature blue-veined cheese. Innov. Food Sci. Emerg. Sci. 11:68-77. https://doi.org/10.1016/ j.ifset.2009.10.009.

Walstra, P. 1993. The syneresis of curd. Pages 141-191 in Cheese: Chemistry, Physics and Microbiology. P. F. Fox, ed. Springer, Boston, MA. https://doi.org/10.1007/978-1-4615-2650-6_5.

Yordanov, D. G., and G. V. Angelova. 2010. High pressure processing for foods preserving. Biotechnol. Biotechnol. Equip. 24:1940-1945. https://doi.org/10.2478/V10133-010-0057-8. 